\title{
Type and Density of Bacterial and Fungal Bioaerosols and Particles in Inside and Outside of Hospital: Modeling of Dispersion and Antibiotic Resistance of Bacterial Bioaerosols
}

\section{Ameneh Yousefzadeh}

Kurdistan University of Medical Science: Kurdistan University of Medical Sciences

Afshin Maleki ( $\square$ maleki43@yahoo.com )

Kurdistan University of Medical Sciences https://orcid.org/0000-0001-8261-8717

\section{Saeed Dehestani Athar}

Kurdistan University of Medical Science: Kurdistan University of Medical Sciences

\section{Ebrahim Darvishi}

Kurdistan University of Medical Science: Kurdistan University of Medical Sciences

Manochehr Ahmadi

Kurdistan University of Medical Science: Kurdistan University of Medical Sciences

\section{Ebrahim Mohammadi}

Kurdistan University of Medical Science: Kurdistan University of Medical Sciences

\section{Van Tai Tang \\ Ton Duc Thang University}

\section{Rasoul Nassiri Kalmarzi}

Kurdistan University of Medical Science: Kurdistan University of Medical Sciences

Hajar Kashefi

Kurdistan University of Medical Sciences

\section{Research Article}

Keywords: Particulate matter, bioaerosol, antibiotic resistance, hospital, air pollution

Posted Date: June 1st, 2021

DOI: https://doi.org/10.21203/rs.3.rs-496093/v1

License: (9) This work is licensed under a Creative Commons Attribution 4.0 International License. Read Full License 


\section{Abstract}

The study of loading rate of microorganisms in the space of hospital inside and outside to evaluate their impacts on physical health of patients and staff, as well as to find out the source of possible infections and allergies stemming from the presence of bioaerosols is of great importance. In total, 262 bacterial and fungal samples were collected from the air of the wards of Tohid Hospital, Sanandaj, Iran. Also, suspended particles were measured by Particle Mass Counter (model: TES-5200). Parameter such as relative humidity and temperature were recorded by using TES-5200 device. To identify bacteria, some biochemical and molecular tests were conducted. And, for the identification of fungi, microscopic and macroscopic characteristics were used. The highest and lowest densities of the bioaerosols were observed in lung and operating wards (336.67 and $15.25 \mathrm{CFU} / \mathrm{m}^{3}$ ). Moreover, the highest and least concentrations of particles were seen in the emergency and operating wards, respectively. The most common fungi isolated from the hospital air were Penicillium (24.7\%), Cladosporium (23. 4\%), Aspergillus niger (13.3\%) and Aspergillus Flavus (11.4\%). Furthermore, the highest concentration of the isolated bacterium was Staphylococcus hemolyticus $(31.84 \%)$. And, the bacteria had the most resistance to antibiotic gentamicin.The general average of air pollution of the hospital to bioaerosols in quantitative terms was higher than that suggested by international organizations. Considering the high concentration of bioaerosols and particles in the hospital studied, provision of optimal conditions (like temperature, humidity, suitable ventilation and intelligent air conditioning system) and imposing a restriction in the entrance of the wards can be utilized to reduce the amount of pollution.

\section{Introduction}

Suspended particles contain biological and non-biological substances that can be transported by air flow (Sepahvand et al. 2016). Bioaerosols are defined as aerosols or any other gas containing a living component or particles released from a living organism. The size of bioaerosols varies from $0.1 \mu$ to about $100 \mu$. In a general classification based on the nature of bioaerosols, they can be divided into the following three categories: a) viruses and parasites b) living organisms including: bacteria and fungi c) parts of microorganisms or products derived from them such as spores, plant pollen, endotoxins and animal allergens (Zare sakhoydi 1395).

Fungi and bacteria constitute a large range of microorganisms in a hospital environment. Level and variety of biological pollution in the hospital environment depend on various factors such as the number and activities of visitors, patients, design of hospital rooms, disinfection methods, dust in the air and so forth (Saadoun et al. 2008). Today, the transmission of viruses and pathogenic bacteria is recognized as an important route for a wide range of nosocomial infections. According to studies estimations, $10 \%$ of nosocomial infections are airborne infections and $16 \%$ of intensive care unit (ICU) infections are due to airborne pathogen transmission (Mirhoseini et al. 2016). Some recent studies have shown that up to $10-20 \%$ of all endemic nosocomial infections may be transmitted through airborne infections. Also, 11\% of all deaths in low-income countries are due to lower respiratory tract infection for indoor air pollution (Gizaw et al. 2016). Hospital buildings, as dynamic environments, may be affected by season, weather conditions, design and operation of indoor ventilation systems, moisture penetration, microbial load in the open air, and the number of residents, visitors, and human activities (Verde et al. 2015). In this case, hospital environments require special attention to ensure the health of indoor air quality (IAQ) to protect patients and healthcare staff against nosocomial infections and occupational diseases (El-Sharkawy \&Noweir 2014).

In hospitals, Staphylococcus aureus and Streptococcus pyogenes are a global public health problem. These two species are common pathogens in hospitals that may cause severe invasive infections (Gizaw et al. 2016). Park et al. who assessed the levels of of Airborne Bacteria, Gram-Negative Bacteria, and Fungi in Hospital Lobbies, stated that all the lobbies were infected (Park et al. 2013).

Antibiotic resistance is a major problem in the treatment and control of infections. Extensive use of antibiotics in recent years has made some bacteria resistant to broad-spectrum antibiotics from different groups; at present, the presence of multidrug-resistant strains of antibiotics (MDR) is the main problem in the treatment of bacteria such as Pseudomonas aeruginosa in important hospital wards such as burns and intensive care (Adabi et al. 2015). Due to the necessity of antibiotic resistance and its consequences on human health, the resistance of 11 types of bacteria isolated from indoor air to the antibiotics amoxicillin, cefixime, ciprofloxacin, azithromycin, gentamicin, doxycycline and sulfamethoxazole were evaluated in this study. 
As the rate of nosocomial infections is directly related to the density and type of bioaerosols, thus, determining the type and density of these microorganisms is of particular importance (Massoudinejad et al. 2014). The amount of airborne microorganisms inside the hospital in this study was performed in the internal wards of men and women, infectious, lung, neurology, emergency, ICU, operating room, burns as well as air outside the hospital. Since suspended particles are carriers of biological agents like bacteria and fungi, quantitative analysis of them (PM1, PM2.5, PM4, PM7, PM10) and their relationship with microbial density is of great importance (Cao et al. 2014). Therefore, suspended particle matters were also performed. The modeling of the dispersion of bio-aerosols in different wards and identification of bacterial isolates by the PCR method were also determined.

\section{Materials And Methods}

Study area

The Sanandaj composting plant is located at a distance of $8 \mathrm{~km}$ from Sanandaj, Iran. Figure 1 shows the geographical location of the biocomposting plant and its units. This plant receives municipal wastes collected from residential areas of the city. The waste is mainly composed of food waste, paper, wood, street wastes, ferrous and non-ferrous metals, glasses, bottles, plastics, etc.

Sampling method

In this study, samples were selected from a number of wards inside the hospital (men's ward, women's ward, lung, neurology, infectious, ICU, burns, operating room, emergency) and the air outside the hospital to determine the quantity and type of bacterial and fungal contaminants as well as particles. The sampling was performed in such a way that all wards of the studied hospital were covered. Sampling in this study was performed in four times in autumn and winter. Inside the hospital, three stations were considered in each ward and in the air outside the hospital, three stations were considered, which sampling was done for four times in each station. In order to evaluate and determine microbial airborne contaminants in the air of different wards, a sampling device (Quick Take-30, SKC, USA) was used. The sampling method with this device is through impact. This device consists of a biostage having 400 holes and a plate containing the culture medium is placed in it. The flow rate of the sampling pump was $28.3 \mathrm{~L} / \mathrm{min}$ and the duration of sampling air inside and outside the hospital was selected using trial and error at different times for the flow rate to increase the accuracy of the results.

Finally, the sampling time was 20 and 5 min for bacteria and fungi, respectively. For sampling, the sampling device was located at a height of $1.5 \mathrm{~m}$ above the ground and at a distance of more than $1 \mathrm{~m}$ from the walls and obstacles (Nunes et al. 2005). Regarding the samples taken from the hospital grounds, these samples were taken from a distance of at least $50 \mathrm{~m}$ from the streets.

Before sampling, all devices were first washed in disinfectant solution (70\% alcohol) and then autoclaved for 30 min at standard temperature and pressure. Next, all items were transported in sterile packages to the hospital. In the hospital and in the ward, the prepared sampling series of the device cap with an alcohol pad was sterilized and the sampling was performed. The culture medium used in this study contained bacterial agents: tryptic soy agar (TSA) and fungi: malt extract agar (MEA) containing the antibiotic chloramphenicol.

Particles and dust were measured by Particle Mass Counter (model: TES-5200). This device has the ability to measure particles in two modes: count mode to measure the number of particles in the sizes of $0.5,0.7,1,2.5,4,5,7$ and $10 \mu \mathrm{m}$ and mass mode to measure the volume density level in accordance with the standards PM1, PM2.5, PM4, PM7, PM10. At the same time, the measured volume or flow shows the sample air temperature in terms of ${ }^{\circ} \mathrm{C}$ or ${ }^{\circ} \mathrm{F}\left(10-40^{\circ} \mathrm{C}\right)$ and the relative humidity $(20-20 \%)$ of the sample air. The flow rate is $2.83 \mathrm{~L} / \mathrm{min}$ or $0.1 \mathrm{CF} / \mathrm{min}$. In other words, the sampling time is $1 \mathrm{~min}$.

Bacterial identification

The collected samples were transferred to an incubator $\left(35-37^{\circ} \mathrm{C}\right.$ ). After 40 to $56 \mathrm{~h}$ (average $48 \mathrm{~h}$ ), the culture medium containing the bacteria was examined, and the colonies formed on them were counted. In order to count the colonies, ocular and colony 
counter methods were used. For bacteriological examination, the cultured samples were taken out of the incubator and all the plates were tested for colony growth, morphology, color and appearance. For microscopic examination of bacteria as well as morphologically (cocci or bacilli) some biochemical tests such as gram staining, catalase, oxidase, urease, OF and IMViC were performed.

Evaluation of antibiotic-resistant bacteria

In this study, antibiotic resistance test was performed for 18 types of the bacteria isolated from the air of different wards of the hospital. The antibiotics selected in this study were as follows: cefixime, amoxicillin, azithromycin, gentamicin, doxycycline, ciprofloxacin and sulfamethoxazole. The bacteria were cultured on tryptic soy agar (TSA) medium containing seven types of the antibiotics. The prepared media containing the desired bacteria were transferred to plates, and two antibiotic discs were placed inside each plate.

Bacterial identification by PCR method

The total genomic DNA of the bio-aerosol samples were extracted by standard phenol-chloroform method as described elsewhere (Krumins et al. 2014). UV spectrophotometry was used to quantitative and qualitative analysis of extracted DNAs at 260 and 280 $\mathrm{nm}$, respectively. $16 \mathrm{~S}$ ribosomal-ribonucleic acid polymerase chain reaction (PCR) was applied for bacterial identification in culture-positive samples. Universal oligonucleotides primers specifically designed for detection of 16S rRNA gene region were used (Mulla et al. 2018): Forward: 27f (5'-AGAGTTTGATCMTGGCTCAG-3'); Reverse: 1492R (5'-GGTTACCTTTGTTACGACTT-3'). For amplifications of $16 \mathrm{~S}$ ribosomal-DNA, reaction mixtures contain around $100 \mathrm{ng}$ of template DNA, $12.5 \mu \mathrm{L}$ of $2 x$ PCR master mix containing appropriate PCR buffer, $2.5 \mathrm{mM}$ concentration of each dNTPs, 0.2 units/ $\mu$ Ampliqon Taq DNA polymerase, 1.5 $\mathrm{mM}$ of $\mathrm{MgCl}_{2}$ and a $20 \mathrm{pmol}$ of each forward and reverse PCR primers in a total volume of 50 microliters were prepared. In each PCR run, a negative control consisted of all PCR components except for template bacterial DNA. The PCR conditions were as follow: after $5 \mathrm{~min}$ initial denaturation step at $94^{\circ} \mathrm{C}, 33$ cycles of denaturation for 30 seconds at $94^{\circ} \mathrm{C}$, annealing for 30 seconds at $55^{\circ} \mathrm{C}$, and extension for 90 seconds at $72^{\circ} \mathrm{C}$, followed by a final extension for $10 \mathrm{~min}$ at $72^{\circ} \mathrm{C}$ were run in a thermal cycler machine (Biometra, Germany). The amplification products were electrophoresed in $1.5 \%$ agarose gel at TBE and visualized using a UV transilluminator.

The PCR Products were gel purified by QIAquick PCR purification kit and Sanger sequencing were done by Microsynth (Switzerland). Sequence editing and assembly were done by DNA Dragon 1.6.0 (http://www.dna-dragon.com/). Multiple sequence alignment was carried out by clustal W method (Thompson 1994) in MEGA X (MEGA and Evolution).

Fungal identification

The fungal samples were incubated at 25 to $27^{\circ} \mathrm{C}$ for $72 \mathrm{~h}$. After this period, the number of colonies on the plates was counted. For the initial differential identification of fungi, their macroscopic features including surface and back staining of colonies and their microscopic characteristics including shape, size and location of spores were used.

Modeling the dispersion of concentrations of bio-aerosols in different wards

Modeling methods are commonly applied to project the dispersion and distribution of contaminants in environments. SURFER is a contouring and 3D surface mapping software program running under Microsoft Windows. This software quickly and easily converts data into outstanding contour, surface, wireframe, vector, image, shaded relief, and post maps. The SURFER software is a data dispersion modeling software, which can be applied in different areas. This software can predict and test data using the power training from input data. The data dispersion in this method is determined on the basis of different counters and layers of data. In this method, the data dispersion and their scale are determined by the coloring. In this study, $70 \%$ of the data were used for training the networks, $30 \%$ were used for testing the software and predictive model.

Statistical analysis

Pearson correlation coefficient at a significant level $(a=0.05)$ was used to establish the relationship between the bacteria and fungi concentrations in the air and the parameters such as temperature, wind speed and direction, moisture percentage, number 
of suspended particles. Meanwhile, the kruska-wallis test was used to determine the possible relationship between the bioaerosol concentration and the change of seasons and location.

\section{Results And Discussion}

In hospital environments, various factors such as temperature, relative humidity, hospital building design, ventilation system, and indoor population density and disinfection methods can affect the concentration of air pollutants (Mousavi et al. 2019). In this study, a total of 262 samples of bacteria and fungi from 10 hospital wards were examined. As a result, 14 bacterial species and 12 fungal species were identified.

Particle distribution in different wards of the hospital

Particle density in different wards of the hospital is influenced by factors such as the number of beds in each room, the number of patients in the hospital room, the rate of ventilation, the number of staff and the proximity to a street (Shokri et al. 2016). Due to the effect of particles on the density of bacterial and fungal bioaerosols, the sampling time of suspended particles coincided with the fungal and bacterial sampling. The results of this study showed that the average particle concentration in about $90 \%$ of the hospital wards and ambient air was higher than the 24-hour World Health Organization (WHO) and United States Environmental Protection Agency (USEPA) standards, which are and, respectively. In accordance with our observations, Rezaei et al. reported the concentration of PM10 and PM 2.5 suspended particles in the air of some wards inside the air around a hospital in Tehran above the recommended limits of the WHO and USEPA and stated that the quality of indoor air was affected by the ambient air (Rezaei et al. 2013).

In this study, the effect of temperature as one of the meteorological parameters on the concentration of suspended particles was investigated. Based on the results, the average temperature of the hospital wards was $24.77^{\circ} \mathrm{C}$. Centers for Disease Control and Prevention (CDC) and Healthcare Infection Control Practices Advisory Committee (HICPAC) recommend temperatures of $21-24^{\circ} \mathrm{C}$ and $23-27^{\circ} \mathrm{C}$, respectively, in winter and summer for most wards of hospitals (Chinn \&Sehulster 2003).

In the infectious part, in all concentrations studied, temperature and particle concentration had a significant relationship and a positive correlation coefficient, i.e. with increasing temperature in the infectious part, the concentration of suspended particles increased. This increase in the concentration of particles in the ICU and infectious wards can be due to reasons such as the large number of patients admitted to the ward, high traffic of companions, use of non-sterile personal equipment by companions and patients, lack of proper ventilation system, and type of disease. Therefore, temperature can be considered as a factor in increasing the concentration of particles. Shokri et al. reported a significant positive relationship between the temperature and humidity and the concentration of suspended particles in the sizes of 0.3, 2.5 and $10 \mu \mathrm{m}$ in indoor air (Shokri et al. 2016).

According to the results, there was no direct and significant relationship between moisture and particle concentrations in different diameters in all the wards. The most polluted part in terms of the presence of particles in different sizes was related to the emergency ward for reasons such as a wide range of patients and their congestion in the emergency ward compared to other wards or high traffic of clients, lack of hygiene, smoking and inadequate ventilation. Unlike, it was found that the operating room befitted from the best conditions, which can be due to the high level of health standards such as limited traffic, fewer patients, closed entrance to the other wards and proper ventilation, sterilization and disinfection of surfaces and premises. In agreement with our study, Nikpei et al. reported that the highest number of particles with diameters of 0.3 and $2.5 \mu \mathrm{m}$ was for the emergency ward (Shokri et al. 2016).

Fungi

According to the data from Table 1, the lung ward was the most infected part of the hospital in terms of the presence of airborne fungi. Even so, in this section, the number of colonies was higher than $200 \mathrm{CFU} / \mathrm{m}^{3}$. Also, the operating room with the lowest number of grown colonies had the best air quality among the other wards of the hospital. The low level of pollution in the operating room can be due to the importance and sensitivity of this ward compared to other wards inside. The hospital has a high level of compliance with health standards such as limited traffic, fewer patients, frequent purification of room air by high- 
efficiency particulate air (HEPA) filters, suction of outside air by exhaust fan and sterilization of equipment and surfaces by ultraviolet devices.

In this study, the number of colonies measured in different wards of the hospital was higher than the standard recommended by the WHO, which is 50 colonies. Although the health hazards posed by bioaerosols have been identified and proven, no specific permissible limits are recommended for this category of airborne pollutants and the values provided are the recommended values. The large number of hospital beds and the consequent increase in the number of patients and visitors, as well as the inadequate ventilation system in some patients' rooms and the poor quality of indoor air, are among the factors providing conditions for growth and proliferation of fungal spores (Azizifar et al. 2009, Kamali Sarwestani et al. 2017). Some clients' activities such as talking, walking in the wards, sneezing and coughing consecutively also increase the spread and consequently cause the load of bioaerosols in the air of the hospitals to increase (Hoseinzadeh et al. 2013). Azizifar et al. reported that the average concentration of fungi in different wards of the hospital was $200 \mathrm{CFU} / \mathrm{m}^{3}$. In the current study, the highest and lowest infections were related to the infectious ward and operating room (ear, nose, throat and eyes) with the average concentrations of 300 and $94 \mathrm{CFU} / \mathrm{m}^{3}$, respectively (Azizifar et al. 2009).

Among the fungal species observed in the study hospital, Penicillium, Cladosporium, Aspergillus Niger and Aspergillus Flavus were the most abundant, respectively. Similarly, Cladosporium, Penicillium and Aspergillus have been reported as the dominant species isolated from hospital environments. For example, Azizifar et al., who quantitatively and qualitatively evaluated fungal air pollution in different wards of the hospital, stated that the highest percentage of fungi observed in the hospital air were Penicillium (36.36\%) and Cladosporium (24.74\%), and Aspergillus niger (17.97\%) (Azizifar et al. 2009).

Table 1

Mean and standard deviation of fungal pollution load $\left(\mathrm{CFU} / \mathrm{m}^{3}\right)$ in the hospital

\begin{tabular}{|lllllllllll|}
\hline Ward & $\begin{array}{l}\text { Internal } \\
\text { men }\end{array}$ & $\begin{array}{l}\text { Internal } \\
\text { women }\end{array}$ & Lung & Neurology & Infectious & Burn & ICU & $\begin{array}{l}\text { Operating } \\
\text { room }\end{array}$ & Emergency & $\begin{array}{l}\text { Outside } \\
\text { air }\end{array}$ \\
\hline $\begin{array}{l}\text { Average } \\
\left(\mathrm{CFU} / \mathrm{m}^{3}\right)\end{array}$ & 62.20 & 124.25 & 223.09 & 154.09 & 63.27 & 42.70 & 55.55 & 0.42 & 106.42 & 52.73 \\
\hline $\begin{array}{l}\text { Standard } \\
\text { Deviation } \\
\left(\mathrm{CFU} / \mathrm{m}^{3} \text { ) }\right.\end{array}$ & 26.72 & 283.79 & 164.98 & 25.38 & 12.66 & 24.07 & 13.03 & 0.50 & 71.23 & 27.51 \\
\hline
\end{tabular}

The reason for the predominant presence of these three types of fungal species in the air inside the hospital can be stated that Penicillium, Cladosporium and Aspergillus fungi have high growth ability in different climatic conditions and by producing small, light spores remain in air. Conidia spores of these fungi also have an outer layer rich in hydrophobic protein, which leads to their further suspension in the air. These fungi have the ability to supply the carbon and hydrogen they need from a variety of sources, allowing them to survive longer in a variety of conditions. However, other fungi such as Alternaria and Ulocladium and some other fungi produce smaller, larger and heavier spores that tend to settle faster and are found at different levels (Alangaden 2011, Vonberg \&Gastmeier 2006).

The most and least fungal species observed in the present study were Penicillium and cranosporium and yeasts and scopolariopsis (Fig. 1). Several species of fungi have been observed in some stations. Fungal species of Aspergillus flavus, Alternaria, Penicillium and Geotrichum were mostly observed in the burn ward. In the ICU ward, Alternaria, Aspergillus niger and Ulocladium were mostly observed. Furthermore, in the emergency ward, the most observed species were Cladosporium, Penicillium, Rhizopus and Ulucladium.

Bacteria

Bacterial densities in the hospital wards ranged from 3.75 to $214.2 \mathrm{CFU} / \mathrm{m}^{3}$. According to the results presented in Table 2, men's ward and operating room with an average of $148 \pm 65$ and $14.83 \pm 16.05 \mathrm{CFU} / \mathrm{m}^{3}$ had the highest and lowest levels of contamination load. The main reason can be considered the observance of high level of health standards in the operating room compared to other hospital wards, as well as disinfection and proper ventilation. 
It should be noted that the average density of bacterial bioaerosols in the men's and women's wards, lungs and burns was higher than the standard recommended by the WHO $\left(100 \mathrm{CFU} / \mathrm{m}^{3}\right)$ (Fig. 2). According to the study by Valedeyni Asl et al., the density of bacterial bioaerosols in the air of Ardabil teaching hospitals was higher than the standards suggested by the WHO and USEPA. Factors such as population density, ventilation and health conditions of the building and the type of hospitalized patients, the presence of companions and staff can increase the density of bacteria compared to the proposed standard (VALEDEYNI et al. 2018).

Table 2

The mean of bacterial number observed in each ward

\begin{tabular}{|llll|}
\hline Ward & Average & Standard Deviation & $\mathbf{p}$ \\
\hline Internal men & 148.00 & 65.154 & \multirow{2}{*}{0.071} \\
\hline Internal women & 142.00 & 54.513 & \\
\cline { 1 - 3 } Lung & 113.58 & 37.378 & \\
\hline Neurology & 92.66 & 28.053 & \\
\hline Burn & 133.50 & 39.877 & \\
ICU & 90.33 & 18.712 & \\
\hline Infectious & 100.08 & 99.235 & \\
\hline Operating room & 14.83 & 16.059 & \\
\hline Emergency & 38.91 & 20.887 & \\
\hline Outside air & 84.50 & 59.046 & \\
\hline
\end{tabular}

Considering that Tohid Hospital in Sanandaj is an educational and medical center, it can be said that one of the reasons for the high density of bacterial bioaerosols in this hospital, in addition to the high volume of patients, can be the presence of many students. In Masoudinejad's study, a significant linear correlation was observed between patients and population density with the concentration of bacteria, which showed the larger the population, the higher the number of bacteria in the air (Massoudinejad et al. 2015).

Environmental parameters are one of the factors affecting the microbial population in hospital environments. Due to the fact that temperature changes in the studied areas are in the small range (24 to 25), it does not have a significant effect on the concentration of bacteria. Also, the lack of correlation between the percentage of relative humidity and the number of bacteria in this study can be attributed to the small range of relative humidity changes (23-27) at the sampling points, which is 40 to $60 \%$ less than the proposed standard (Rafiee et al. 2018).

Since only floors, walls and some pieces of equipment are washed with disinfectants when washing and disinfecting parts, the humidity of the air can increase due to washing, which facilitates the growth and persistence of microorganisms. On the other hand, if air conditioning is used in hospitals, it can reduce the humidity; because humidity is effective in the growth of bioaerosols and if air conditioning is used, bioaerosols that are in the outside air do not penetrate into the indoor environment and therefore the amount of indoor air pollution will be reduced. As it turns out, different findings have been presented regarding the effect of temperature and humidity on the growth of bacteria in the air of hospitals, which requires more and more detailed studies in this field.

It was found that there was no significant relationship between the number of particles observed in different sizes and concentrations and the number of bacteria observed. That is, particle concentrations and different particle sizes had no effect on the microbial load. The findings of this study are inconsistent with some previous studies. Mirhosseini et al. reported that there was a significant relationship between 1 to $5 \mu \mathrm{m}$ particles and the density of bacterial bioaerosols in the surgical and ICU wards (Mirhoseini et al. 2015). 
According to the results of differential tests, most of the bacteria isolated from the air of the wards in Tohid Hospital was Staphylococcus hemolyticus (Fig. 3). In a study by Solomon et al., performed in Ethiopia, Staphylococcus coagulase-negative bacteria, Staphylococcus aureus, Enterococcus faecalis, Enterococcus faecium, Acinetobacter, Escherichia coli, Pseudomonas aeruginosa were detected in a university teaching referral hospital (Solomon et al. 2017).

Staphylococci are among the opportunistic microorganisms that are detected in most areas, and since Staphylococcus species are part of the natural flora of the skin and nose, it seems that their high rate in this study due to the increase in population, especially during the presence of companions. Coagulase-negative staphylococci include species of the genus Staphylococcus that lack the coagulase enzyme, and the most important species are Staphylococcus epidermidis, Staphylococcus saprophyticus, and Staphylococcus hemolyticus. These species are not highly toxic, but are an important cause of infections in high-risk groups.

Staphylococcal infections can be transmitted through contact with an infected person or the patient's belongings, including clothing, towels, and bedding. The staff of hospitals are the most important and common carriers of them, from one sick person to another (DADASHI et al. 2015). Staphylococcus hemolyticus is the second most common coagulase-negative staphylococcus as a pathogen in normal valvular endocarditis, septicemia, bacteremia, bone and joint infections, urinary tract infections, wound infections, and opportunistic infections. Unlike other CoNS, Staphylococcus hemolyticus is resistant to vancomycin (Sivagnanasundaram et al. 2019).

Bacillus was one of the bacteria identified in the hospital wards. The ability to form spores enables Bacillus species to tolerate harsh environmental conditions and conventional disinfection methods. Some bacilli are part of the opportunistic natural flora of the human gastrointestinal tract and are dangerous to immunocompromised patients such as those with AIDS and diabetes. Micrococcus luteus is also known as a nosocomial pathogen and causes pneumonia, endocarditis, meningitis and intracranial hemorrhage (Naddafi et al. 2009, Sivagnanasundaram et al. 2019).

In this study, Escherichia coli was less common than Staphylococcus, Bacillus and Pseudomonas. It has been documented that Escherichia coli is involved in the development of diseases such as urinary tract infections, sepsis, pneumonia, gastroenteritis and meningitis (Sivagnanasundaram et al. 2019).

According to the results, the total average of bioaerosols in this hospital was $184.38 \mathrm{CFU} / \mathrm{m}^{3}$. The highest density of bioaerosols was in the lung ward with the amount of contamination $\left(336.67 \mathrm{CFU} / \mathrm{m}^{3}\right)$ and the lowest was in the operating ward with the amount of contamination $\left(15.25 \mathrm{CFU} / \mathrm{m}^{3}\right)$. Following that, the women's ward and then neurology had the highest pollutant density.

Evaluation of bacterial resistance to antibiotics

The results of antibiotic resistance of 18 common bacteria detected in this study have been presented in Table 3. Among them, the highest drug resistance was observed in Staphylococcus hemolyticus and aureus. Staphylococcus hemolyticus had shown resistance to five types of GM-CP-AZM-AMX-CFM antibiotics.

Table 3

Antibiotic-resistant bacteria

\begin{tabular}{|ll|}
\hline Type of bacteria & Antibiotic resistant \\
\hline Staphylococcus hemolyticus & GM- CP- AZM- AMX- CFM \\
\hline Staphylococcus aureus & GM- AMX-CFM \\
\hline Pneumococcus & SXT- CFM- GM \\
\hline Staphylococcus CONs (epidermidis) & CP- GM \\
\hline Staphylococcus CONs (Saprophyticus) and Staphylococcus CONs (Epidermidis) and Bacillus & CFM \\
\hline Lateus micrococcus & AMX \\
\hline Streptococcus pyogenes & GM \\
\hline
\end{tabular}


Staphylococcus aureus is a ubiquitous organism and has a high potential for causing various diseases in humans due to its high resistance to adverse environmental conditions. The development of resistance to various antibiotics in strains of

Staphylococcus aureus causes many problems in the treatment of diseases related to these microorganisms, thus, it is necessary to know the pattern of resistance of these microorganisms in the treatment of related diseases (Saha et al. 2008). Antibiotic resistance of Staphylococcus aureus to GM-AMX-CFM antibiotics has been observed. In the study by Saadat et al., the highest resistance of Staphylococcus aureus to amoxicillin was found, which is close to the findings of this study (Saadat et al. 2014). Also, Staphylococcus epidermis was resistant to CP, GM and CFM. In the study by Nourbakhsh and Momtaz, Staphylococcus epidermis was the most resistant to the antibiotics erythromycin, ciprofloxacin, clindamycin and tetracycline, which is consistent with the results obtained in the present study (Nourbakhsh \&Momtaz 2016). In the study by Dadashi et al., on the frequency and profile of antibiotic resistance of Staphylococcus coagulase negative specimens in the medical staff of an army hospital, $62 \%$ of the isolates were CNS strains (Staphylococcus negative coagulase). The highest resistance in these strains (epidermidis, saprophyticus, hemolyticus and hominis) against oxacillin: 90, 94, 89 and 100\%, and gentamicin: 86, 81, 65 and 100\%, respectively, and the highest susceptibility was observed in mupirocin $(100,100,100$ and $100 \%)$, vancomycin $(85,88,78$ and 100\%) (DADASHI et al. 2015).

According to the findings of this study, the bacteria were most resistant to the antibiotic gentamicin, so that about $70 \%$ of the bacteria tested for antibiotic resistance were resistant to gentamicin. After that, the highest resistance of bacteria was to cefixime, amoxicillin and ciprofloxacin, respectively. Based on the results of this study, while identifying the underlying factors and appropriate measures to control antibiotic-resistant bacteria, it is recommended for coagulase-negative strains of Staphylococcus, especially species such as Staphylococcus hemolyticus to avoid prescribing high-resistance antibiotics such as gentamicin, cefixime, amoxicillin, and ciprofloxacin to these strains.

The PCR assay was performed for two samples of the bacteria that had the highest resistance and the highest presence among the identified bacteria. Sample number one, resistant to five types of antibiotics (ciprofloxacin, gentamicin, azithromycin, amoxicillin, cefixime) and sample number two was resistant to four types of antibiotics (gentamicin, azithromycin, amoxicillin, cefixime). The results of molecular PCR test for both samples showed Staphylococcus hemolyticus. The reason for selecting these two samples was the highest resistance to antibiotic discs, the highest frequency and repetition among the samples taken during the study, as well as different appearance characteristics. NCBI nucleotide BLAST search (http://blast.ncbi.nlm.nih.gov/Blast.cgi) showed that sequences share highest identity with Staphylococcus haemolyticus, Bacillus subtilis, Bacillus licheniformis (Fig. 5).

Modeling the dispersion of pollutants using SURFER software

Maps prepared based on data from particle measuring stations in lung, neurology, infectious and open air wards showed that the emission and concentration of pollutants in the eastern parts had a higher dispersion. In other areas, including burns, ICU, emergency and men's and women's wards, the distribution of pollutants in all measuring stations in these areas was high. According to the results, the entrance of the infectious ward (east side) has the highest particle density, which can be due to the location of the waiting room at the entrance of the ward and high traffic in these areas (Fig. 6). However, the distribution of pollutants in other wards was evenly distributed.

Counter curves on the maps related to the distribution of bacteria in the hospital wards showed that in the men's and women's wards, the concentration of bacteria in the stations located in the northern and central parts of the wards was higher than the southern parts. The number of bacteria in the operating room was measured in the range of $2-36 \mathrm{CFU} / \mathrm{m}^{3}$. The counter curve numbers show that the bacterial dispersion was lower in most parts of the measuring stations and the less contour lines in the section. The central part shows the high concentration of bacteria. In the previous sections, it was stated that the lowest bacterial density was in the operating room.

In the intensive care unit, bacterial densities were measured in the range of $72-128 \mathrm{CFU} / \mathrm{m}^{3}$, and counter curves in the bacterial spreading map in this ward showed that bacterial densities were measured at the measuring points in the western part of the ward, which is located at the entrance to the ward, was more than the eastern parts (end of the ward). Figure 7 shows the possible spread of bacteria in some parts of the hospital. 
According to the maps obtained from the spreading of bacteria in the intensive care unit (Fig. 7), the density of these microorganisms in the measured points located in the western part of the ward (entrance part) was more than the eastern parts (end of the ward). Due to the proximity of the entrance of the two infectious diseases and special care, the high presence of particles and bacteria in this area can be due to high traffic and lack of natural and artificial ventilation in this place.

The fungal spread distribution map in the intensive care unit shows that the rate of spread and dispersion of fungal aerosols is higher in the measuring points located in the western part and flow of pollutants has decreased while moving to the central and eastern (end of the ward). This situation indicates the concentration of fungi in the western part (entrance) of the intensive care unit. As mentioned above, the spread of bacteria has been higher in the intensive care unit in the western part. The following figure (Fig. 8) shows the possible spread of fungi in some parts of the hospital.

One of the reasons for the high presence of pollutants at the entrance of the ICU can be the lack of proper and adequate ventilation in this area, as well as the high traffic of the population and patients. On the other hand, in multi-bedroom wards of the hospital, including the intensive care unit, because there is a risk of infection of neighboring patients, reasonable measures should be taken to control the infection. In a study by Ching et al. carried out on reducing the risk of airborne infections in hospitals using hospital curtains, hospital curtains were called as physical barriers to disease transmission is potentially a simple but effective way to reduce the risk of infection; in this study, the effectiveness of hospital curtains in preventing the transmission of airborne diseases in hospital rooms has been investigated using numerical modeling. Among all case studies, it was found that the use of curtains between two beds can reduce the peak contaminant concentration for each neighboring patient in a bioaerosol dispersion process by up to $65 \%$ (Ching et al. 2008).

\section{Conclusion}

According to the results obtained, the general average of the bioaerosols in the hospital studied was $184.38 \mathrm{CFU} / \mathrm{m}^{3}$. The most densities of the bioaerosols were observed in the lung ward $\left(336.67 \mathrm{CFU} / \mathrm{m}^{3}\right)$, followed by the women and neurology. And, the least density was seen in the operation room $\left(15.25 \mathrm{CFU} / \mathrm{m}^{3}\right)$. It was found that the air quality in some wards of the hospital did not have a suitable status. Although the hospital benefits from a central ventilation system (exhaust fan), which covers all the wards, the system may suffer from a suitable operational and executive standard. Therefore, the system should be assessed closely in terms of principles of ventilation design. Since the Ecofan system and suction of inside air to outside and for ventilation and the entrance of fresh air to the inside, natural air without any pretreatment is used, thus, the quality of the inside air may be impacted and pollutants may be entered. Since the hospital lacks a suitable guideline and standard regarding the concentration of bacterial and fungal pollution inside the hospital air, it is vital to pay adequate attention to employ these standards by the responsible authorities. Most of the hospitals in Iran, like the hospital studied in the current research, lack a system for air treatment; therefore, enough equipment should be installed. Naturally, other affecting parameters like the standard of the number of beds to area, the physical sanitation of the hospital environment, optimum use of disinfectants, periodical disinfection of air flow path and channels to prevent microorganism growth and the training of staff should be taken into account.

\section{Declarations}

\section{Ethics approval and consent to participate}

Not applicable

\section{Consent for publication}

Not applicable

\section{Availability of data and materials}

All data generated and analyzed during this study are included in this published article.

\section{Competing interests}

Page $10 / 18$ 
The authors declare that they have no conflict of interest.

\section{Funding}

This study was funded by Kurdistan University of Medical Sciences and Environmental Health Research Center

\section{Authors' contributions}

AY- Execution of the experiments and initial draft of the manuscript

AM-Conceptualization, methodology, investigation, writing the original draft of manuscript

SD- Methodology and analysis

ED- Methodology and analysis

MA- experiments, analysis

EM- experiments, analysis

VTT- review and editing of the manuscript

RNK- Methodology and analysis

HK- interpretation of data

\section{Acknowledgements}

This article was extracted from the MSc dissertation of the first author. The authors would like to thank Kurdistan University of Medical Sciences and Environmental Health Research Center for its financial support provided for this research work (IR.MUK.REC.1397/226).

\section{References}

1. Adabi M, Talebi Taher M, Arbabi L, Afshar M, Fathizadeh S, Minaeian S, Moghadam-Marageh N, Majidpour A (2015): Determination of antibiotic resistance pattern of Pseudomonas aeruginosa strains isolated from patients with burn wounds. Journal of Ardabil University of Medical Sciences 15, 66-74

2. Alangaden GJ (2011): Nosocomial fungal infections: epidemiology, infection control, and prevention. Infectious Disease Clinics 25, 201-225

3. Azizifar M, Jabbari H, Naddafi K, Nabizadeh R, Tabaraie Y, Solg A (2009): A qualitative and quantitative survey on airtransmitted fungal contamination in different wards of Kamkar Hospital in Qom, Iran, in 2007. Qom University of Medical Sciences Journal 3

4. Cao C, Jiang W, Wang B, Fang J, Lang J, Tian G, Jiang J, Zhu TF (2014): Inhalable microorganisms in Beijing's PM2. 5 and PM10 pollutants during a severe smog event. Environmental science \& technology 48, 1499-1507

5. Ching W-H, Leung M, Leung D, Li Y, Yuen P (2008): Reducing risk of airborne transmitted infection in hospitals by use of hospital curtains. Indoor and Built Environment 17, 252-259

6. Chinn RY, Sehulster L (2003): Guidelines for environmental infection control in health-care facilities; recommendations of CDC and Healthcare Infection Control Practices Advisory Committee (HICPAC).

7. DADASHI A, FIROOZI F, SANJARBEIGI N, ZAHEDI NA, AMIRI H, NIKOOEI M (2015): PREVALENCE AND SUSCEPTIBILITIES OF COAGULASE NEGATIVE STAPHYLOCOCCI ISOLATED IN HEALTH CARE WORKERS IN A MILLITARY HOSPITAL, KERMANSHAH.

8. El-Sharkawy MF, Noweir ME (2014): Indoor air quality levels in a University Hospital in the Eastern Province of Saudi Arabia. Journal of family \& community medicine 21,39 
9. Gizaw Z, Gebrehiwot M, Yenew C (2016): High bacterial load of indoor air in hospital wards: the case of University of Gondar teaching hospital, Northwest Ethiopia. Multidisciplinary respiratory medicine 11, 24

10. Hoseinzadeh E, Samarghandie MR, Ghiasian SA, Alikhani MY, Roshanaie G (2013): Evaluation of bioaerosols in five educational hospitals wards air in Hamedan, During 2011-2012. Jundishapur Journal of Microbiology 6

11. Kamali Sarwestani Z, Dasdar A, Agha Kuchak Afshari S, Gerami Shoar M, Hashemi SJ, Pakzad R, Ardi P, Abdollahi A, HaghiAshtiani M-T, Mahmoudi S (2017): Evaluation of fungal air contamination in selected wards of two tertiary hospitals in Tehran, Iran. Tehran University Medical Journal TUMS Publications 75, 299-306

12. Krumins V, Mainelis G, Kerkhof LJ, Fennell DE (2014): Substrate-dependent rRNA production in an airborne bacterium. Environmental Science \& Technology Letters 1, 376-381

13. Massoudinejad M, Ghajari A, Hezarkhani N, Aliyari A (2014): Survey of Environmental Bioaerosols in ICU ward of Taleghani Hospital in Tehran by Petri-dish trapping technique and Bioaerosol Sampler in 2013. Journal of Safety Promotion and Injury Prevention 2, 133-9

14. Massoudinejad MR, Ghajari A, Hezarkhani N, Aliyari A (2015): Survey of Fungi Bioaerosols in ICU ward of Taleghani Hospital in Tehran by Petri-dish trapping technique and Bioaerosol Sampler in 2013. Irtiqā-yi īminī va pīshgīī az mașdūmiyat/ha (ie, Safety Promotion and Injury Prevention) 3, 147-154

15. Mirhoseini SH, Nikaeen M, Khanahmad H, Hatamzadeh M, Hassanzadeh A (2015): Monitoring of airborne bacteria and aerosols in different wards of hospitals-Particle counting usefulness in investigation of airborne bacteria. Annals of Agricultural and Environmental Medicine 22

16. Mirhoseini SH, Nikaeen M, Khanahmad H, Hassanzadeh A (2016): Occurrence of airborne vancomycin-and gentamicinresistant bacteria in various hospital wards in Isfahan, Iran. Advanced biomedical research 5

17. Mousavi MS, Hadei M, Majlesi M, Hopke PK, Yarahmadi M, Emam B, Kermani M, Shahsavani A (2019): Investigating the effect of several factors on concentrations of bioaerosols in a well-ventilated hospital environment. Environmental monitoring and assessment 191, 407

18. Mulla SI, Hu A, Sun Q, Li J, Suanon F, Ashfaq M, Yu C-P (2018): Biodegradation of sulfamethoxazole in bacteria from three different origins. Journal of environmental management 206, 93-102

19. Naddafi K, Rezaei S, Nabizadeh R, Younesian M, Jabbari H (2009): Density of Airborne Bacteria in a Children Hospital in Tehran. Iranian Journal of Health and Environment 1, 75-80

20. Nourbakhsh F, Momtaz H (2016): An Investigation of Antibiotic Resistance Pattern in the Strains of Methicillin-resistant Staphylococcus epidermidis Isolated From Clinical Samples in Isfahan Province, Iran. Qom Univ Med Sci J 10, 68-74

21. Nunes ZG, Martins AS, Altoe ALF, Nishikawa MM, Leite MO, Aguiar PF, Fracalanzza SEL (2005): Indoor air microbiological evaluation of offices, hospitals, industries, and shopping centers. Memórias do Instituto Oswaldo Cruz 100, 351-357

22. Park D-U, Yeom J-K, Lee WJ, Lee K-M (2013): Assessment of the levels of airborne bacteria, gram-negative bacteria, and fungi in hospital lobbies. International journal of environmental research and public health 10, 541-555

23. Rafiee A, Hoseini M, Shabani H, Shahedi A (2018): Assessment of the density and type of the bio-aerosols associated with nosocomial infection in different wards of the selective AJA hospitals in Tehran. EBNESINA 19, 45-52

24. Rezaei S, Naddafi K, Jabbari H, Yonesian M, Jamshidi A, Sadat A, Raygan Shirazinejad A (2013): Relationship between the particulate matter concentrations in the indoor and ambient air of the Tehran children hospital in 2007. Iranian Journal of Health and Environment 6, 103-112

25. Saadat S, Solhjoo K, Norouz-nejadfard MJ, Kazemi A, Rouhi R, Mardaneh J (2014): The frequency of Staphylococcus aureus among Shiraz hospital personnel and determination of their antibiotic sensitivity pattern. ISMJ 17, 916-926

26. Saadoun I, Al Tayyar IA, Elnasser Z (2008): Concentrations of airborne fungal contaminations in the medical surgery operation theaters (OT) of different hospitals in northern Jordan. Jordan J Biol Sci 1, 181-4

27. Saha B, Singh AK, Ghosh A, Bal M (2008): Identification and characterization of a vancomycin-resistant Staphylococcus aureus isolated from Kolkata (South Asia). Journal of medical microbiology 57, $72-79$

28. Sepahvand A, Godini H, Omidi Y, Tarrahi M, Rashidi R, Basiri H (2016): Investigation of fungal bioaerosols and particulate matter in the teaching-medical hospitals of Khorramabad City, Iran during 2015. Iranian Journal of Health and Environment 9 , 
$115-126$

29. Shokri S, Nikpey A, Varyani AS (2016): Evaluation of hospital wards indoor air quality: the particles concentration. Journal of Air Pollution and Health 1, 205-214

30. Sivagnanasundaram P, Amarasekara R, Madegedara R, Ekanayake A, Magana-Arachchi D (2019): Assessment of Airborne Bacterial and Fungal Communities in Selected Areas of Teaching Hospital, Kandy, Sri Lanka. BioMed Research International 2019

31. Solomon FB, Wadilo FW, Arota AA, Abraham YL (2017): Antibiotic resistant airborne bacteria and their multidrug resistance pattern at University teaching referral Hospital in South Ethiopia. Annals of clinical microbiology and antimicrobials 16, 29

32. Thompson JD (1994): Improving the sensitivity of progressive multiple sequence alignment through sequence weighting, position-specific gap penalties and weight matrix choice. Nucleic Acids Res 22, 4673-4680

33. VALEDEYNI AF, HAZRATI S, ARZANLOU M, FAZLZADEH M (2018): ASSESSMENT OF BACTERIAL BIO-AEROSOLS TYPES AND ITS CONCENTRATION IN THE AMBIENT AIR OF EDUCATIONAL HOSPITALS OF ARDABIL UNIVERSITY OF MEDICAL SCIENCES IN 2016.

34. Verde SC, Almeida SM, Matos J, Guerreiro D, Meneses M, Faria T, Botelho D, Santos M, Viegas C (2015): Microbiological assessment of indoor air quality at different hospital sites. Research in microbiology 166, 557-563

35. Vonberg RP, Gastmeier P (2006): Nosocomial aspergillosis in outbreak settings. Journal of Hospital Infection 63, 246-254

36. Zare sakhoydi MJ (1395): Guidelines for evaluating bio-aerosols in the workplace. Health and Environment Center, Ministry of Health and Medical Education - Student Publications, Hamedan

\section{Figures}

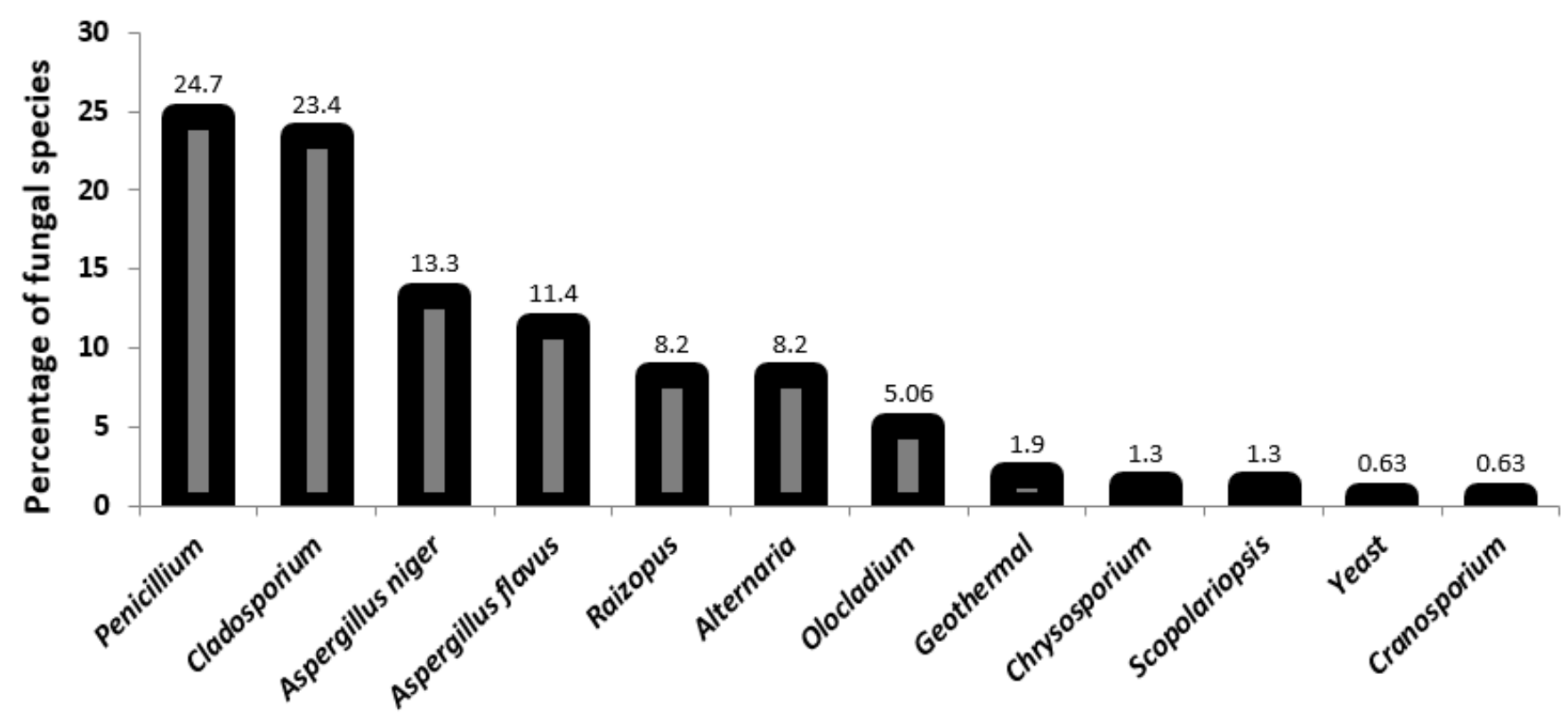

Different fungal species

Figure 1

Frequency distribution of fungal species isolated in different wards of the hospital 


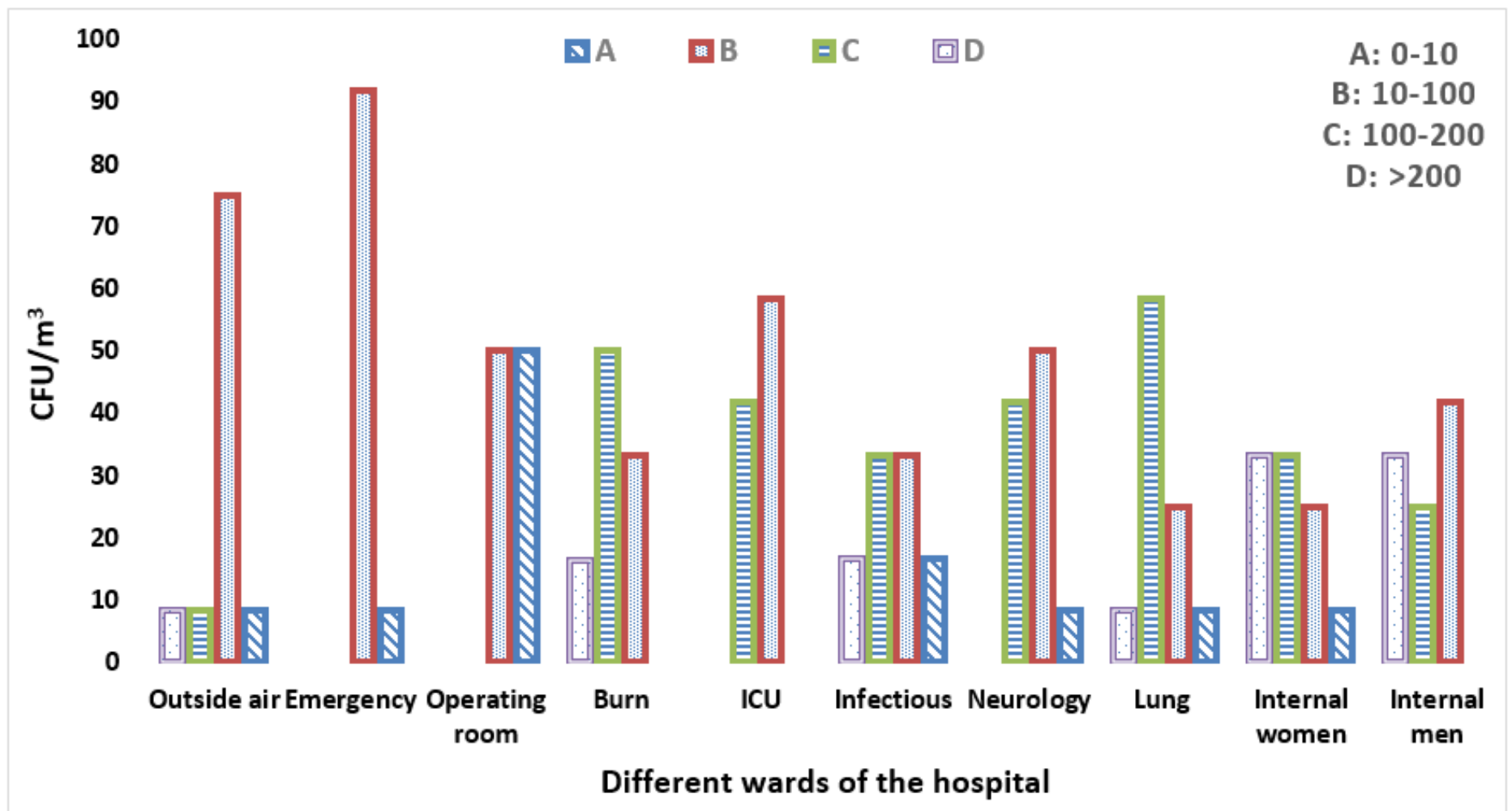

Figure 2

The percentage of bacterial colonies of the sampling points in different surfaces: EU GMP standard

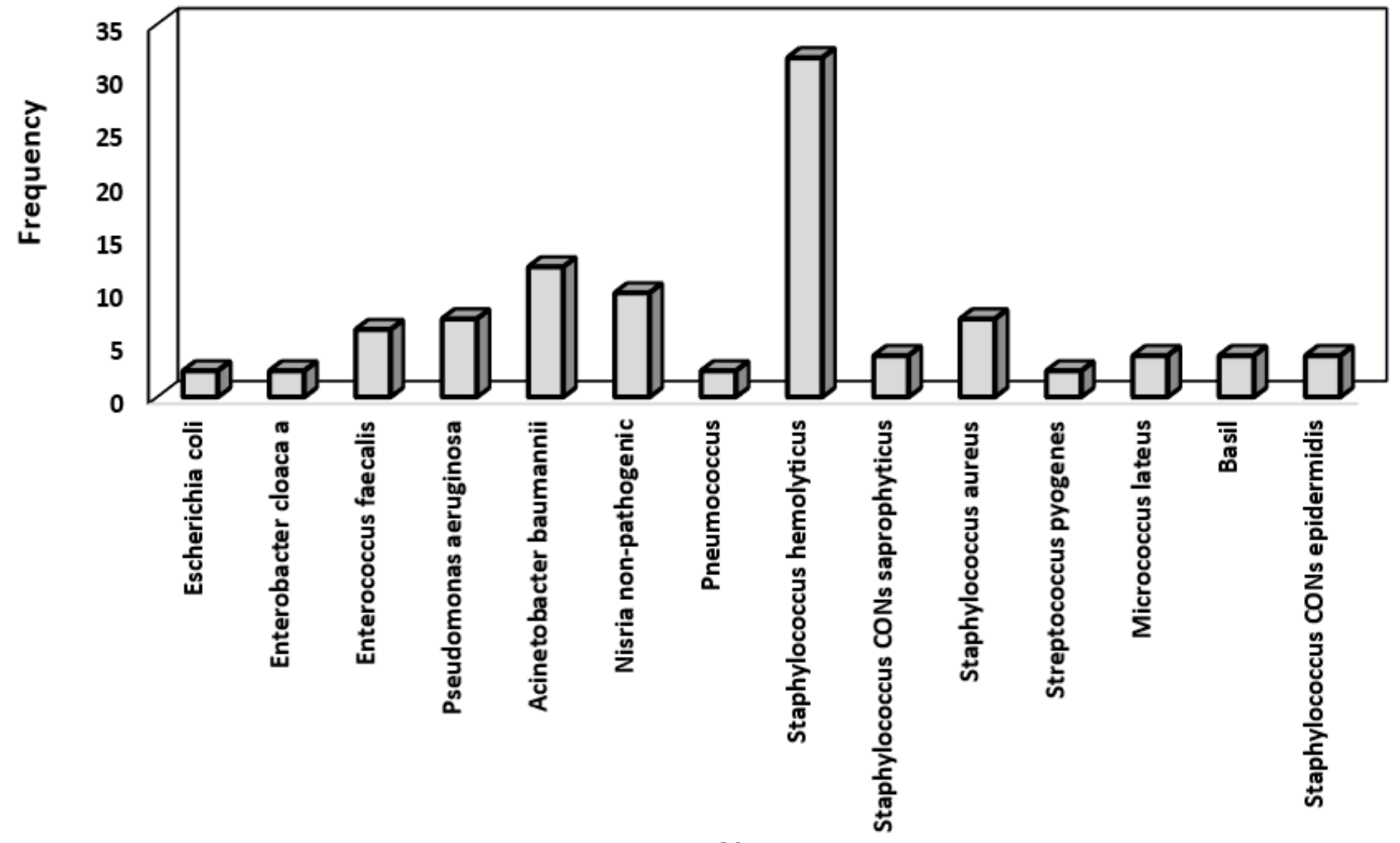

Type of bacteria

Figure 3 


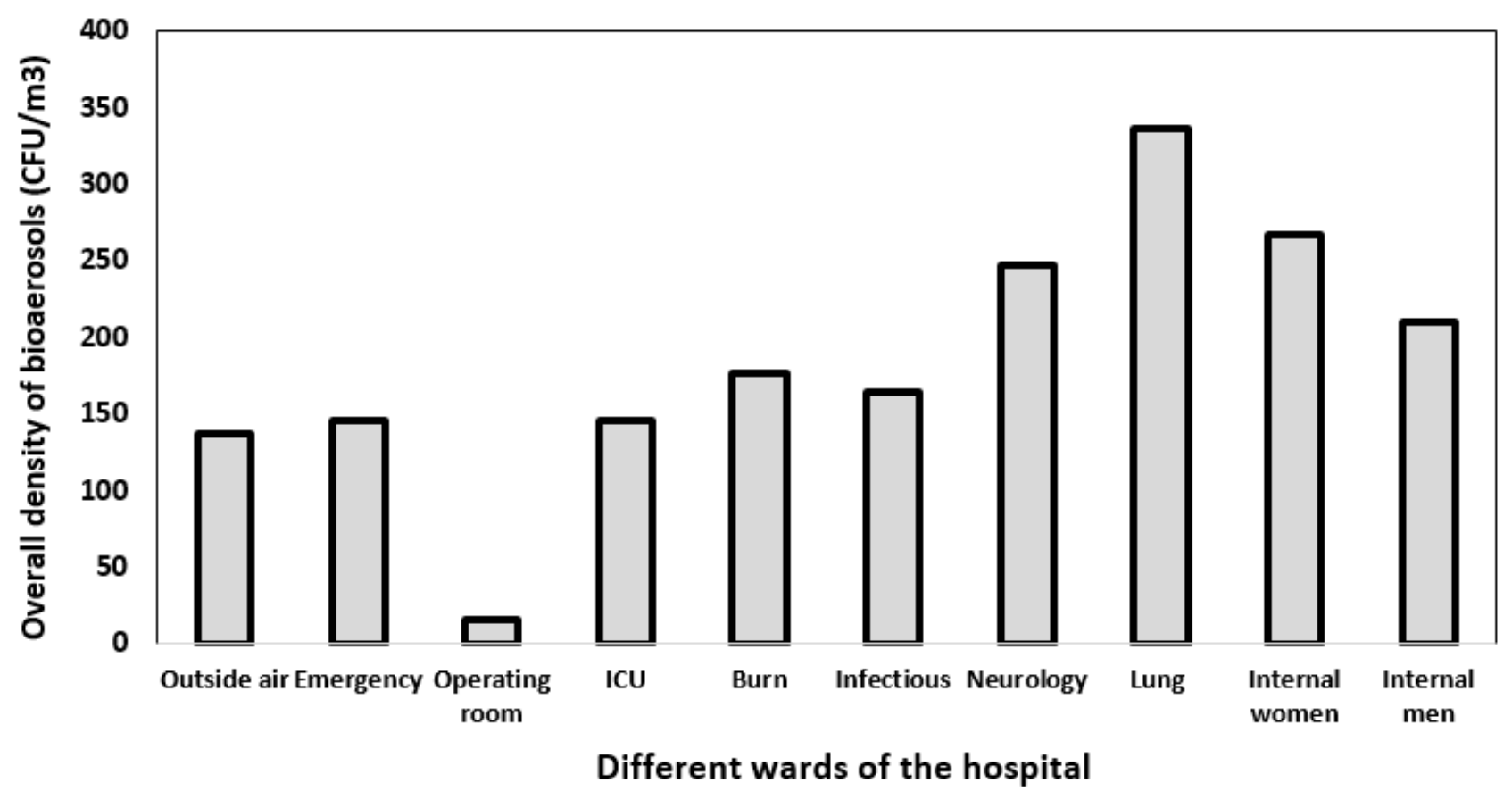

Figure 4

General density of bioaerosols in each ward of the hospital (CFU/m3)

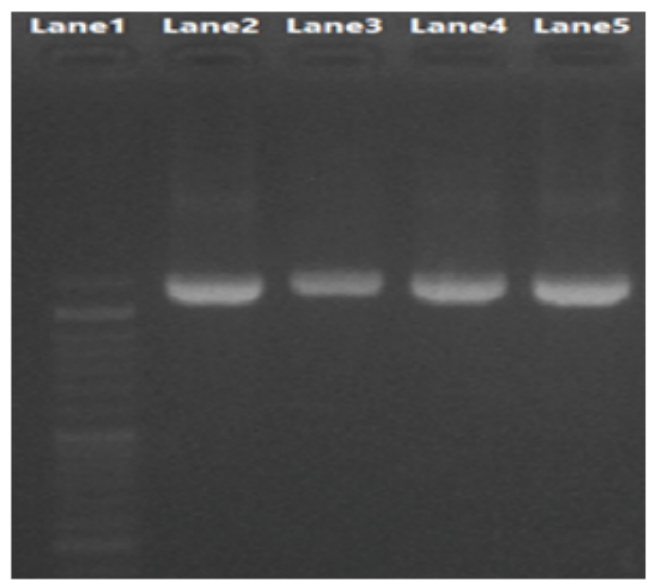

\section{Figure 5}

Agarose gel electrophoresis of the samples amplified by PCR method. The amplification products were run on $1.5 \%$ gel of agarose in an electrophoresis tank. Lane 1 indicates DNA Ladder Marker 100bp, Lane 2-5 indicate the amplified 16S rRNA gene of the bacterial isolate samples (S1-S4). 


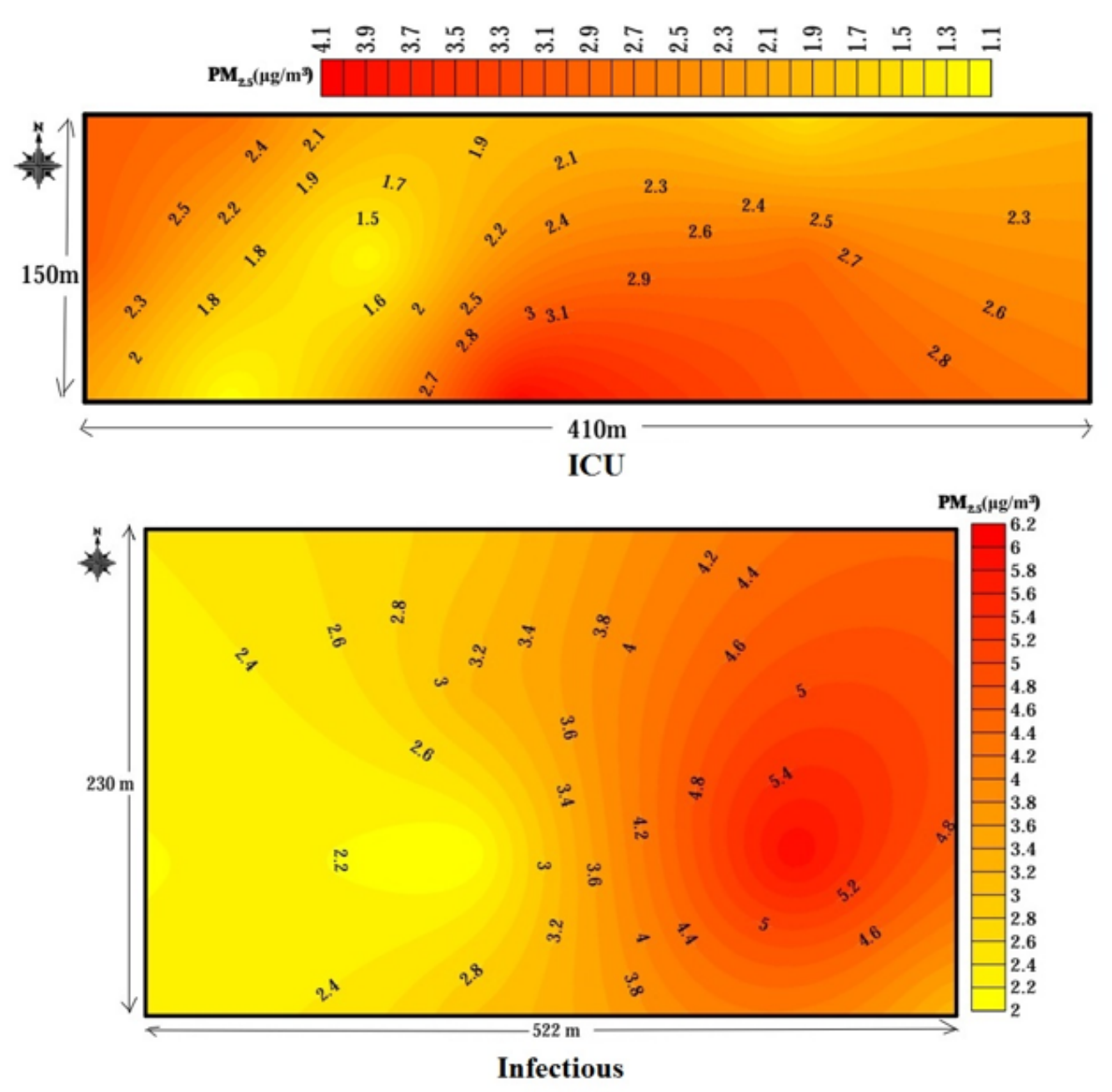

Figure 6

Possible dispersion of particle in each ward of the hospital 


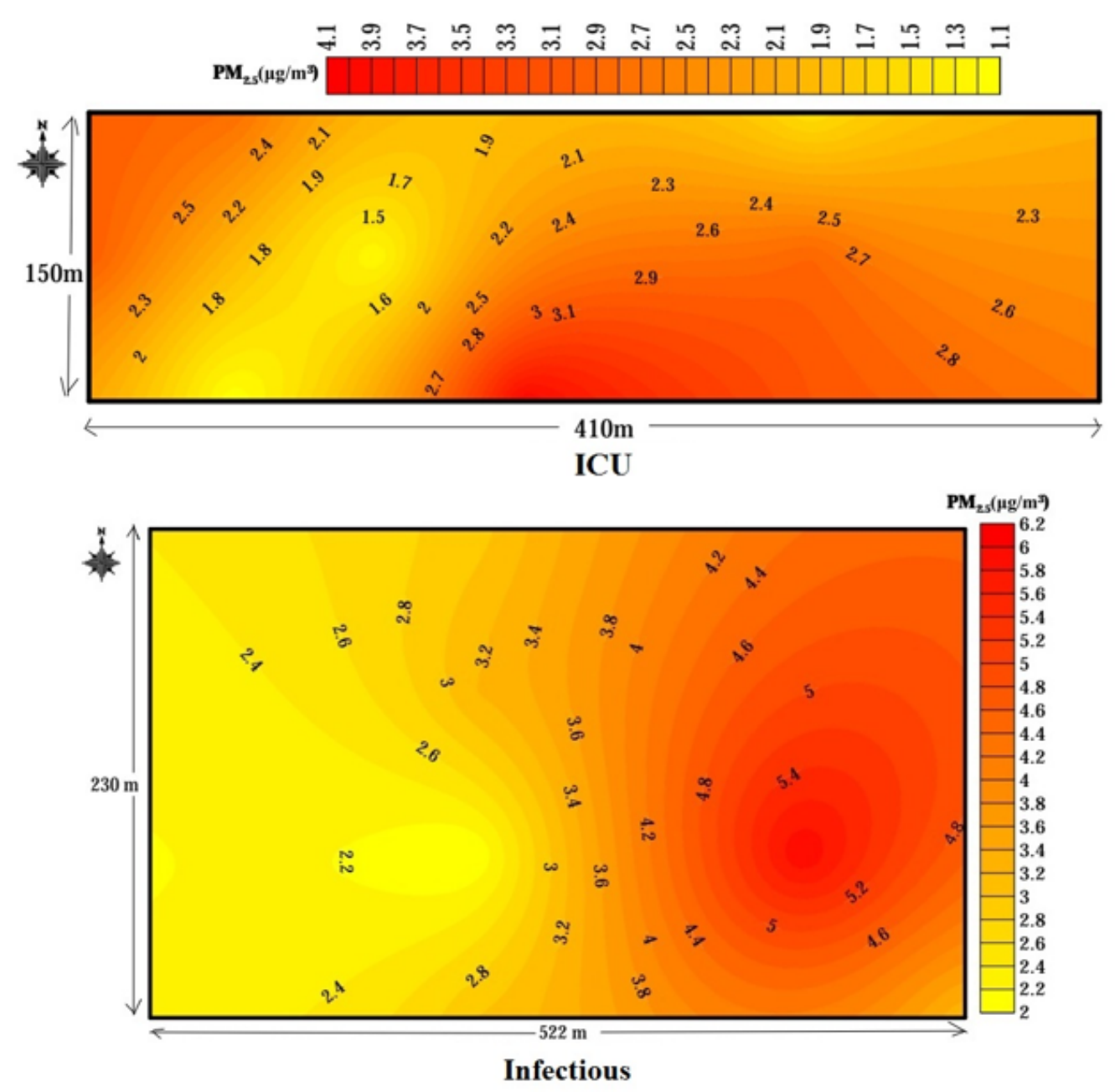

Figure 7

Possible dispersion of bacteria in each ward of the hospital 


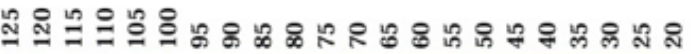

FUNGUS(CFU/m $\left.\mathbf{m}^{3}\right)$
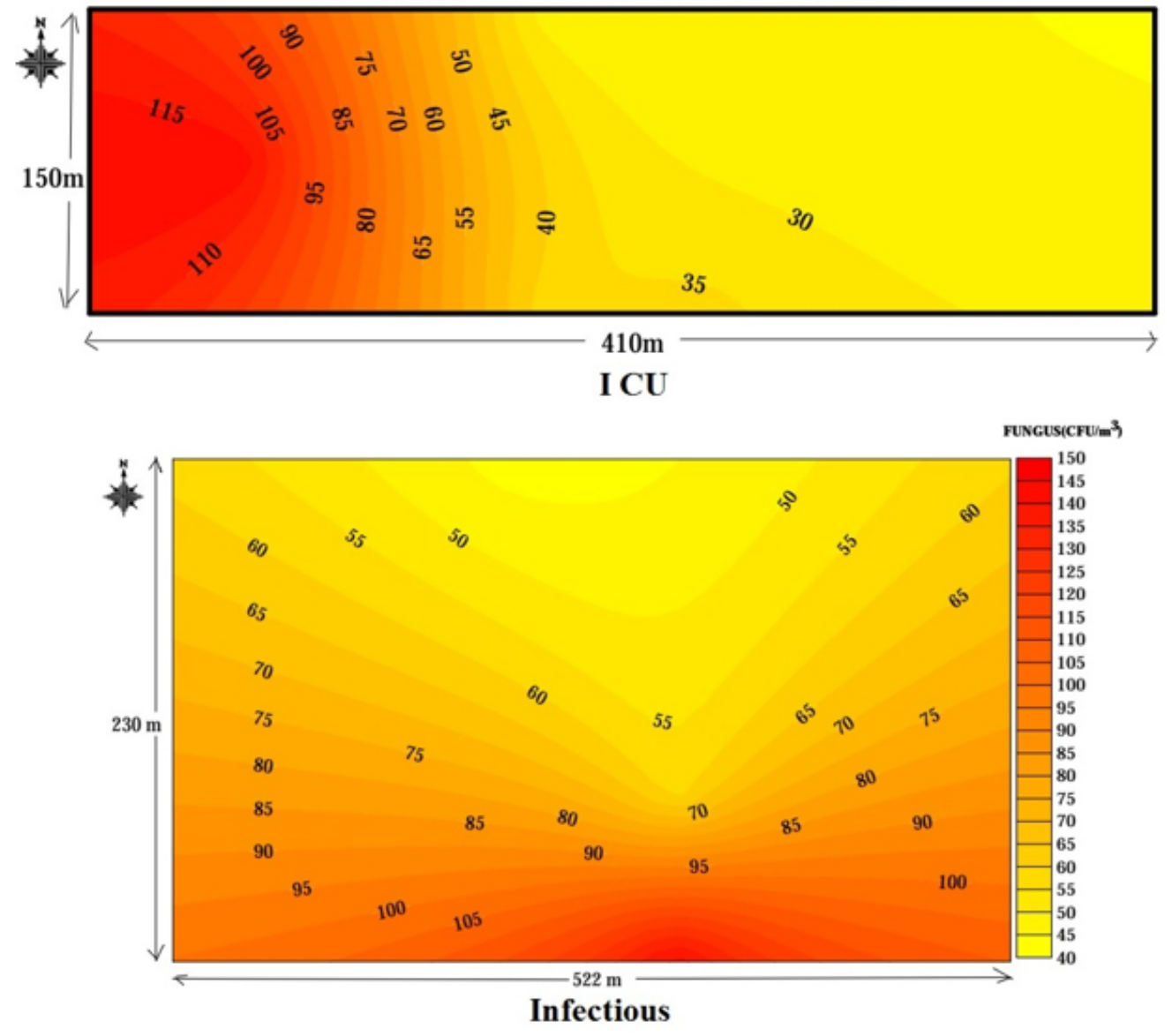

\section{Figure 8}

Possible dispersion of fungi in the ICU ward of the hospital 